\title{
TRANSFORMACIÓN DE LAS FAMILIAS. LA IRRUPCIÓN DEL HIJO ÚNICO
}

\author{
JOAN TAHULL FORT ${ }^{1}$ \\ IOLANDA MONTERO PLAZA ${ }^{2}$
}

Fecha de recepción: febrero 2019

Fecha de aceptación y versión definitiva: octubre 2019

RESUMEN: En los últimos años en los países occidentales, también en España, se está produciendo un proceso de individualización, constatado en múltiples dimensiones, también en el seno de las familias. Progresivamente, los hogares están reduciendo los miembros, apareciendo nuevas tipologías familiares hasta hace muy poco marginales y poco consideradas. La aparición de forma mayoritaria de los hijos únicos está cambiando dinámicas sociales y quizás también estructuras. Para la realización de la investigación se presentan datos cuantitativos oficiales y también se realizan diferentes entrevistas a personas conocedoras de la temática. La opción de muchos padres por tener solamente un hijo está lejos de comportamientos egoístas y narcisistas, al contrario, responde a las necesidades impuestas por la posmodernidad. Pueden ofrecer a sus hijos más y mejores posibilidades de formación para adaptarse a una sociedad futura compleja y cambiante.

PALABRAS CLAVE: Individualización; transformación familia; familia; hijo único.

\section{Transformation of families. The emergence of the only child}

ABSTRACT: In recent years, a process of individualization has been occurring in Western countries, including Spain, and its effects can be seen in many aspects, as well as in the heart of the family. Progressively, the number of children in a household is being reduced, giving way to new familial typologies, which not long ago were marginal and rarely taken into account. The emergence of an only-child majority is changing social dynamics and possibly its structure. For the completion of the investigation, official quantitative data is presented and experts on the topic are interviewed. The choice of many parents to have an only child is far from being considered selfish and narcissistic behavior. On the contrary, it answers the needs imposed on by the postmodern era. They can offer their children a wider range and a better selection of formation possibilities to be able to adapt better to a future society which is complex and changing.

KEY WORDS: Individualization; familial transformation; family; only child.

1 GESEC (Grupo Estudios sobre Sociedad, Salud, Educación y Cultura). Universitat de Lleida (España). Correo electrónico: joantfort@geosoc.udl.cat.

2 Universitat Oberta de Catalunya. Departament d'Educació. Correo electrónico:ymontero@xtec.cat. 


\section{INTRODUCCIÓN}

En los últimos años en las sociedades occidentales se está produciendo un fenómeno de individualización que se extiende a todos los ámbitos sociales y culturales, también a las familias. Progresivamente los datos muestran cómo los hogares están reduciendo sus miembros llegando a ser significativa casas sin hijos o con uno solo. Comprender este cambio de paradigma no debe reducirse a la comprensión de un aspecto, sino que están imbricadas múltiples dimensiones (económica, social, cultural, psicológica...). Abordar esta complejidad está fuera del alcance de la investigación, la cual pretende ponderar y contrastar principalmente el cambio de modelo familiar demasiadas veces poco comprendido y estudiado por los especialistas sociales.

$\mathrm{El}$ artículo tiene el objetivo de describir y reflexionar la evolución de las familias españolas en los últimos años, principalmente las características de los hogares con un solo hijo. También analizar si la irrupción del hijo único en las familias europeas y españolas es una realidad significativa o marginal; además tenemos el objetivo de realizar una comparativa entre las diferentes tipologías familiares y saber cuáles son más comunes en la actualidad. Igualmente, el objetivo de conocer algunas causas de la posible transformación de las familias en los últimos años y específicamente aquellas con un solo hijo. Para abordar la presente investigación se muestran datos cuantitativos sobre el porcentaje de las diversas tipologías de hogares y se establecen relaciones con las posibilidades económicas de cada modelo familiar. Para complementar los datos cuantitativos se han realizado 15 entrevistas (madres de hijos únicos, hijos únicos mayores de edad y profesores) a individuos conocedores de la temática de la zona de Barcelona, Lleida y Girona.

Cabe señalar la escasez de estudios significativos sobre la figura de los hijos únicos. Algunos de los existentes solamente remarcan y repiten antiguos tópicos incrustados en la sociedad, como la afirmación que los hijos únicos son egoístas, narcisistas y solitarios sin ir más allá. La presente investigación pretende humildemente llenar un vacío en las ciencias sociales y estudiar el hijo único integrado en la sociedad posmoderna compleja y dinámica. Se parte de la hipótesis que la opción de los padres por tener solamente un hijo no es solamente una posibilidad egoísta y negativa sino una adaptación a una sociedad diferente de periodos anteriores. Quizás la opción familiar por tener solamente un hijo es una posibilidad útil que ofrece más facilidades de integración y éxito futuro para estos niños. Quizás el hijo único esté en consonancia con las dinámicas de los tiempos posmodernos y con un proceso de constante y radical individualización en las sociedades occidentales. 


\section{FUNDAMENTOS TEÓRICOS}

En la actualidad, en las sociedades avanzadas estamos instalados en la Posmodernidad, caracterizada por la complejidad, la fragmentación, el desorden, las dificultades y un proceso de constante individualización (Tahull, Molina y Montero, 2017). Bauman (2003) considera que estamos incrustados en estructuras sociales líquidas, en las cuales los individuos no tienen referentes estables previsibles y sólidos. Giddens (2000) dice que sentimos una pérdida del sentido colectivo y grupal. Los sujetos se consideran y valoran individualmente, alejándose de consideraciones generales. Los individuos están más aislados y separados y hay un proceso social de continua atomización. Lipovestsky y Charles (2006) afirman que se ha producido una desarticulación del hogar y las relaciones sociales entre miembros de una familia son más complejas y caóticas que en el pasado. Anteriormente, la tradición imponía un orden social que necesariamente debía seguirse, en cambio en la actualidad, los sujetos continuamente deben reajustar sus posiciones y llegar a consensos difíciles y precarios.

Según Beck (1998) el estado del bienestar en los países occidentales sigue un proceso de pérdida de competencias y sustento de los ciudadanos. El Estado deja de ofrecer determinados servicios públicos básicos a las personas y las empresas privadas ocupan su espacio. Elzo (2000) destaca los cambios acaecidos en la organización familiar y la aparición de múltiples tipologías, en algunos casos anteriormente muy minoritarias y en la actualidad relevantes. Allepuz y Rosell (2014) apuntan que en España en los últimos años ha disminuido el riesgo de pobreza de las personas mayores y ha aumentado significativamente para los menores de edad. Consideran la pobreza infantil un elemento preocupante y a tener en cuenta en la actualidad y en el futuro. Todos estos elementos sociales, culturales y económicos tienen múltiples derivadas, uno sería el descenso de la natalidad en los países occidentales (Lo Castro, 2017).

En los últimos años se está produciendo en los países avanzados, también en Europa y España, una caída del índice de fecundidad ${ }^{3}$. La media europea en el año 2017 era de 1,4 hijos por familia, en España de 1,31 hijos, en Italia de 1,34 hijos, en Paraguay de 2,48 hijos.... ${ }^{4}$ Según Daros (2018) los sujetos están ávidos de individualidad para destacar sus diferencias, tener más confort, estar más tranquilos y buscar su realización personal. Según Lo Castro (2017) las familias en la actualidad tienen menos hijos por priorizar

3 Número medio de hijos por mujer.

4 Según datos estadísticos incluidos en el Datos macro, integra información relevante y actualizada de los principales indicadores nacionales. Consulta en: https:// datosmacro.expansion.com/demografia/natalidad?anio=2017 (26 de enero de 2019). 
los adultos su bienestar y tener miedo a perder autonomía, independencia y calidad de vida; también por la incorporación de la mujer al mercado laboral y la escasa atención de los hombres a las tareas domésticas.

El proceso de individualización seguido en las sociedades avanzadas ha cristalizado también dentro de las familias, cambiando y alterando tipologías familiares dominantes en un pasado reciente. Las familias europeas (los 28 países de la Unión Europea) cada vez tienen menos hijos. El 70\% de los hogares europeos (más de 154 millones de hogares) no tienen ningún niño y solo el 30\% tiene alguno. La mitad de los hogares con hijos solamente tienen uno (el $47 \%)$, dos hijos $(40 \%)$ y tres o más $(13 \%)^{5}$. Se está produciendo un vaciamiento y reducción de los miembros de las familias europeas. Según datos del Instituto Nacional de Estadística de España (INE), analizando los tipos de hogar más frecuentes del año 2016, la pareja con un hijo representa el $15,6 \%$ del total de familias, con dos hijos el $15,1 \%$ y con tres hijos o más el 3,1\%. En la actualidad, en España la tipología familiar mayoritaria con hijos es una pareja o un adulto y un hijo. Resulta un cambio destacado en referencia a periodos pasados. Se ha instalado con fuerza el hijo único en las familias europeas y españolas ${ }^{6}$.

Los hogares con un solo hijo tienen peculiaridades y matices respeto a las familias con más. Se han realizado investigaciones para abordar las características psicosociales de los hijos únicos. Pitkeathley y Emerson (1998, 204) destacan que las relaciones en el seno de una familia con un hijo involucran siempre a un adulto (padre y/o madre); en cambio, las familias con más hijos las relaciones tienen una composición más compleja y no involucran necesariamente a un adulto (hay relaciones entre adultos, entre niños y también el niño puede ser observador y juez de una interacción niño-adulto). Los hermanos tienen unas interacciones entre ellos controladas y supervisadas por los padres. Los autores muestran mediante dos figuras las relaciones sociales en las familias con uno y dos hijos:

5 Datos del Instituto de Política Familiar a partir de la información de EUROSTAT. Consulta en: https://docplayer.es/81391860-Familia-en-europa-informe-evolucion-de-la-w-w-w-i-p-f-e-o-r-g.html (26 de enero del 2019).

6 Datos del Instituto Nacional de Estadística de España (2017). Consulta a: http://www.ine.es/prensa/ech_2016.pdf (26 de enero de 2019). 


\section{GRÁFICO 1. INTERACCIONES PADRES HIJO/S}

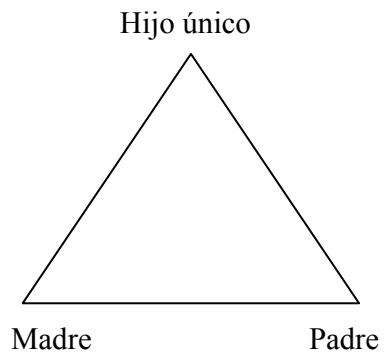

Hijo 1

Hijo 2

Fuente: Pitkeathley y Emerson $(1998,204)$.

El número de miembros de la familia determina la complejidad y la cantidad de interacciones sociales en el hogar. Muchos padres de hijos únicos buscan en el exterior compensar la escasez de estas relaciones y experiencias con actividades variadas... Winnicot (1973), según escribe Lo Castro (2017, 21), en un estudio antiguo, considera que los hijos únicos tienen dificultades para construir su identidad social y relacionarse con sus iguales; pueden llegar a ser más narcisistas y egoístas. Rosenberg y Hyde (1992) dicen que ser hijo único tiene ventajas y no difiere mucho de los niños con hermanos. En todo caso, no todos los hijos únicos son iguales y hay diferencias relevantes entre ellos por temas psicológicos y familiares. Estos autores destacan tres tipos de hijos únicos diferentes: el primero sería etiquetado como hijo normal y bien ajustado; el segundo sería impulsivo; y el tercero sería definido como primogénito. En la misma línea, Bayrakal y Kope (1990) hacen referencia a un tipo concreto de hijo único con su respectiva familia, aquellos que tienen dos miembros (por ejemplo, padre soltero con su hijo). Estos tienen más dificultades y riesgo de vivir situaciones problemáticas y agresivas que aquellas familias más extensas, estables y homogéneas.

En los últimos años se cuestionan estudios antiguos que relacionaban los hijos únicos con ser narcisistas (egoístas y con escasas habilidades sociales entre iguales) y destacan más en la actualidad las mejores posibilidades educativas y sociales y una mejor adaptación de las familias a un contexto social y cultural postmoderno. En un entorno social tradicional y con familias numerosas, el hijo único era minoritario y podía tener rechazo social. Para las familias, tener muchos hijos era un sostén seguro y la tranquilidad de los padres en su vejez. En la actualidad, las familias tienen pocos hijos, algunas ninguno, y hay un proceso de reducción de los miembros, en la línea del individualismo de las sociedades avanzadas. Aranda y Chávez (2017) 
consideran que el número de hermanos no necesariamente influye en el autoconcepto y las habilidades sociales que el niño desarrollará. Los hijos en la actualidad tienen un marco de socialización e influencia más amplio, más allá de la familia, como la escuela, las actividades extraescolares, amigosgrupo de iguales, asociaciones y múltiples y diversas actividades realizadas fuera del entorno familiar. Lien-Tan $(2014,185)$ explica la situación de muchos hogares en China y especialmente con la figura del hijo único instalado mayoritariamente. En este país la estructura familiar dominante es 4-2-1 (cuatro abuelos, dos padres y un niño). Los hijos únicos se han convertido en la opción mayoritaria de las familias chinas y son el centro de atención. Los adultos (abuelos y padres) cuidan y concentran sus energías y expectativas hacia su hijo. La élite económica, política e intelectual china está formada en la actualidad por adultos que han sido hijos únicos.

Falbo y Poston (1993) abordan las posibles diferencias de personalidad y los resultados académicos de alumnos hijos únicos y los que no son en China. Concluyen que no hay diferencias significativas en la mayoría de áreas, aunque destacan que los hijos únicos son mejores significativamente en expresión verbal. Yang, Hou y Wei (2017), en estudios recientes, consideran que los hijos únicos son más inteligentes, creativos y comprometidos que aquellos con hermanos. Además, suelen tener mejores relaciones con sus padres y profesores y están mejor integrados en la escuela. Wang y Zhu (2019) analizaron la relación entre la cantidad de alumnos hijos únicos en una misma clase y el resultado académico global. Concluyen que hay una relación entre la cantidad de alumnos hijos únicos y el mejor o peor rendimiento académico general de todos; en un grupo clase con más alumnos hijos únicos aumenta el rendimiento del conjunto.

\section{METODOLOGÍA}

Para realizar la investigación se ha utilizado información cuantitativa del EUROSTAT sobre los diferentes países europeos y el Instituto Nacional de Estadística (INE) sobre España. Se han buscado datos sobre la distribución (con y sin hijos) de los hogares europeos, la distribución de las familias europeas según el número de hijos, el tipo de hogar más frecuente en España distribuido en diferentes años y el porcentaje de riesgo de pobreza relativa según el tipo de hogar en diferentes años en España.

Los datos cualitativos complementan la información cuantitativa. Se han buscado informantes para entrevistar y para que pudiesen explicar y reflexionar sobre la situación del hijo único. Los entrevistados son de la 
provincia de Lleida, Girona y Barcelona. Algunos viven en un entorno urbano y otros rural, en una proporción del 25\% en áreas rurales y $75 \%$ urbanos. Se han realizado 15 entrevistas en total (5 profesores de primaria y secundaria, 5 madres de hijos únicos y 5 hijos únicos mayores de edad). Todos los informantes son anónimos y conocedores de esta realidad, la cual han vivido en primera persona o en su entorno cercano. No todos los entrevistados aparecen reflejados en la investigación, solamente aquellos fragmentos más representativos y que integraban la perspectiva de los otros entrevistados. En todo caso, sus aportaciones han sido igualmente valiosas, ayudando a contrastar y ponderar la información obtenida.

Un problema destacado de las investigaciones sociológicas es la subjetividad, presentar el estudio desde la mirada del investigador. Se ha pretendido tener una mirada abierta a las diferentes sensibilidades sociales e integrar la complejidad del objeto de estudio. El investigador también debe construir un relato coherente y significativo. No todos los contenidos tienen el mismo valor. El investigador ha ponderado, valorado, contrastado y comparado la información (Ander Egg, 2000).

Todas las entrevistas han durado aproximadamente una hora. Se ha tratado específicamente la figura del hijo único en sus múltiples dimensiones. Se ha llegado a los informantes mediante conocidos, contactando con una llamada telefónica o un correo electrónico. Se les explicaba el objetivo de la investigación y todos los detalles necesarios. En todos los casos, menos uno, no tuvimos dificultades para concretar y realizar las entrevistas. Los lugares de encuentro han sido diversos: sus casas, bares, bancos de una plaza... Nos hemos desplazado a su pueblo o ciudad, adaptándonos a las situaciones planteadas. Se les ha informado que se mantendría el anonimato de sus aportaciones en todas las posibles futuras publicaciones. Se les informó previamente y pidió consentimiento para grabar la entrevista y en ningún caso pusieron ningún inconveniente. Solamente se han transcrito las partes más relevantes y representativas de las entrevistas seleccionadas.

\section{RESULTADOS}

En este apartado se presentan datos cuantitativos y cualitativos sobre la tipología de los hogares europeos y españoles, también se relaciona las diferentes organizaciones familiares por el número de hijos; además se vinculan los diferentes tipos de hogares con el riesgo de pobreza relativa. 


\subsection{Datos cuantitativos}

En el siguiente gráfico se presenta la distribución de los hogares europeos (con hijos/ sin hijos) del año 2016 de los 28 países de la Unión Europea.

\section{GRÁFICO 2. DISTRIBUCIÓN HOGARES EUROPEOS (CON HIJOS/SIN HIJOS)}

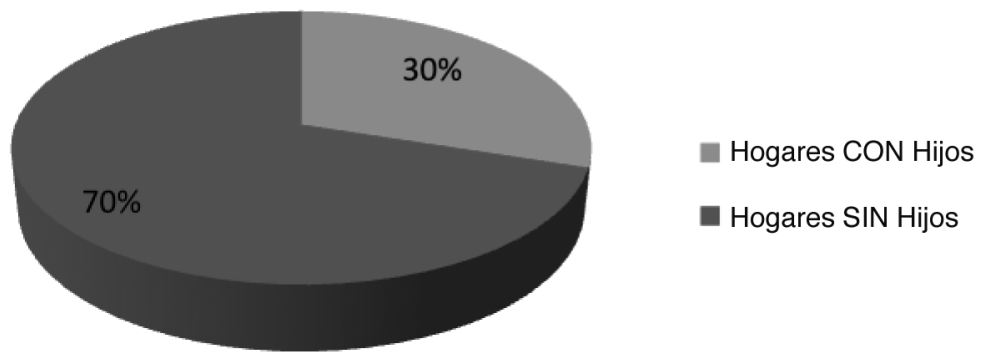

Fuente: Instituto de Política Familiar (IPF) a partir de datos de EUROSTAT.

En el gráfico se muestra la distribución de familias con y sin hijos. El 70\% de los hogares europeos no tienen hijos y el 30\% tiene. Mayoritariamente las familias no tienen hijos. En la tabla presentada a continuación se muestra la distribución de los hogares según el número de hijos de los 28 países de la Unión Europea en el año 2016.

\section{GRÁFICO 3. DISTRIBUCIÓN HOGARES EUROPEOS SEGÚN EL NÚMERO DE HIJOS}

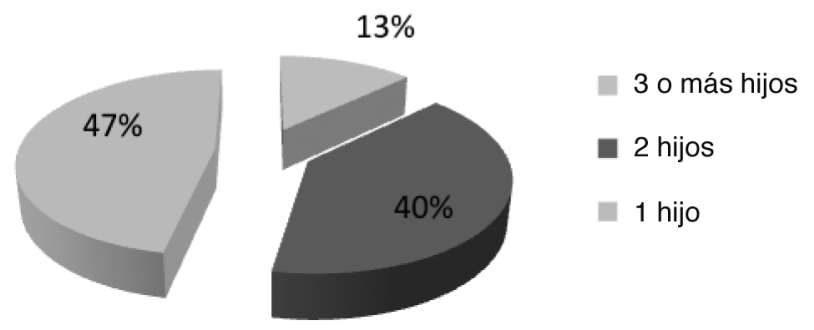

Fuente: Instituto de Política Familiar (IPF) a partir de datos de EUROSTAT. 
Se presentan los porcentajes de las familias europeas con hijos. Las familias con 3 hijos o más representan el 13\% del total de las familias con hijos, los hogares con 2 hijos son el $40 \%$ y aquellas con un solo hijo corresponden al $47 \%$ de las familias con hijos; casi la mitad de las familias con hijos solamente tiene uno. En la siguiente tabla se presentan datos sobre el tipo de hogar más frecuente en España en diferentes años.

TABLA 1. TIPOLOGÍA DE HOGARES ESPAÑOLES

\begin{tabular}{|l|r|r|r|r|}
\hline Tipo de familia & \multicolumn{1}{|c|}{$\mathbf{1 9 9 1}$} & \multicolumn{1}{c|}{$\mathbf{2 0 0 1}$} & \multicolumn{1}{c|}{$\mathbf{2 0 1 1}$} & \multicolumn{1}{c|}{$\mathbf{2 0 1 6}$} \\
\hline Pareja sin hijos & \multicolumn{1}{c|}{. 502.137} & 3.042 .409 & 4.413 .304 & 3.861 .900 \\
\hline Pareja con un solo hijo & 2.277 .417 & 2.606 .233 & 3.368 .830 & 2.878 .400 \\
\hline Pareja con dos hijos & 2.679 .982 & 2.867 .510 & 3.070 .214 & 2.781 .000 \\
\hline Madre con un solo hijo & 564.590 & 829.464 & 1.206 .011 & 673.600 \\
\hline Pareja con tres hijos & 1.139 .432 & 782.743 & 531.105 & 569.400 \\
\hline Madre con dos hijos & 243.082 & 374.086 & 461.379 & 540.000 \\
\hline Padre con un sólo hijo & 117.449 & 211.577 & 319.754 & 305.000 \\
\hline Padre con dos hijos & 50.045 & 83.665 & 121.120 & 113.000 \\
\hline Pareja con cuatro hijos & 570.648 & 211.922 & 100.081 & ------ \\
\hline Madre con tres hijos & 89.640 & 97.597 & 75.422 & 99.000 \\
\hline Padre con tres hijos & 17.687 & 20.488 & 19.254 & 20.000 \\
\hline
\end{tabular}

Fuente: Instituto Nacional de Estadística (INE).

Se muestran datos sobre la evolución de las familias españolas desde 1991 hasta el 2016. En todos los años la tipología mayoritaria es la pareja sin hijos, después en función de los años va cambiando. En 1991 había en España 2.277.417 hogares con un solo hijo y 2.679.982 familias tenían dos. La tipología familiar con hijos mayoritaria era una pareja (padre-madre) y dos hijos. En 2001 había todavía más parejas con dos hijos (2.867.510 hogares) que parejas con uno (2.606.233 hogares). En 2011 había más parejas con un solo hijo (3.368.830 hogares) que parejas con dos (3.070.214 hogares). La misma tendencia continúa en el último año que tenemos datos. En todos los años la organización mayoritaria es la pareja sin hijos y después la pareja con dos hijos. A partir de 2011 la tendencia se modifica, la familia 
con un hijo supera a la de dos, tendencia que continúa hasta el último año que tenemos datos. Respecto al 2016 destacar también el descenso brusco del total de familias, descenso de la población. Sin pretender analizar las causas de forma exhaustiva (no forma parte del estudio), se debe a la fuerte crisis económica instalada en España que ha provocado que muchas familias retornaran a sus países de origen.

En el siguiente gráfico se presenta el porcentaje de riesgo de pobreza relativa según el tipo de hogar en diferentes años en España.

TABLA 2. PORCENTAJE DE RIESGO DE POBREZA RELATIVA SEGÚN LA TIPOLOGÍA DE HOGAR EN ESPAÑA

\begin{tabular}{|l|c|c|c|c|}
\hline & 2015 & 2013 & 2011 & 2009 \\
\hline Hogares sin hijos dependientes a cargo & 16,8 & 14,6 & 17,3 & 15,7 \\
\hline Hogares con hijos dependientes a cargo & 27,4 & 25,9 & 23,8 & 24,8 \\
\hline 1 adulto con 1 o más niños dependientes & 37,5 & 38,0 & 42,1 & 44,2 \\
\hline 2 adultos con 1 dependiente a cargo & 18,4 & 18,8 & 16,3 & 18,7 \\
\hline 2 adultos con 2 dependientes a cargo & 25,6 & 22,9 & 23,5 & 23,1 \\
\hline 2 adultos con 3 o más hijos & 44,0 & 39,4 & 40,2 & 47,5 \\
\hline
\end{tabular}

Fuente: Instituto Nacional de Estadística (INE).

En la tabla se relaciona la tipología familiar con el riesgo de pobreza familiar en diferentes años. Según las características de los hogares hay mayor riesgo de pobreza. En el año 2015 los hogares sin hijos dependientes a cargo tenían el $16,8 \%$ de riesgo de pobreza, aquellos con hijos el $27,4 \%$, un adulto con 1 o más niños dependientes el $37,5 \%$, dos adultos con 1 dependiente a cargo el $18,4 \%$, dos adultos con 2 dependientes el $25 \%$. Hay una relación entre tipología familiar y posibilidades económicas. Según los datos presentados, las familias sin hijos o con uno tienen menos riesgos de caer en la pobreza. Estas familias tienen más recursos y posibilidades para formarles y capacitarles para una sociedad compleja y cambiante.

\subsection{Datos cualitativos}

Presentados los datos cuantitativos generales de las tipologías de los hogares europeos y españoles en diferentes años, mostrando la evolución hasta años recientes, hay una tendencia general de las familias hacia una 
reducción de sus miembros. La pareja sin hijos es el modelo más representativo en todos los años presentados, seguido a partir del año 2011 de la pareja con un hijo. EUROSTAT en la Unión Europea y el INE en España muestran como las parejas principalmente cuando quieren ampliar la familia prefieren tener prioritariamente un hijo. Los gráficos muestran como la figura del hijo único no es un hecho residual y marginal, al contrario, está generalizado y fuertemente implantado en la sociedad.

Seguidamente se presentan las aportaciones de madres con un hijo, hijos únicos mayores de edad y docentes los cuales explicarán y reflexionarán sobre sus vivencias y experiencias del tema abordado. Se empezará por las aportaciones de las madres de hijos únicos, las cuales analizarán las posibilidades y limitaciones de sus hijos. Además, en algunos casos explican los motivos por los cuales no han querido tener el segundo. Las informantes son 5 madres con hijos de diferentes edades y residen en diferentes pueblos/ ciudades de la provincia de Lleida, Girona y Barcelona. Dos viven en un entorno rural y las restantes en un espacio urbano. Solamente se comparten las reflexiones de tres madres, las más representativas y descriptivas de las opiniones de todas. Irene tiene un hijo de 7 años y vive en un pueblo de 1.500 habitantes de la provincia de Lleida, dice:

[...] porque entre el trabajo, la vida estresada que llevamos, etc. Con uno es más que suficiente... Estoy en una oficina y hago horario mañana y tarde. La verdad es que en un pueblo pequeño es un poco limitado pues no pueden escoger a los amigos, hay los que hay. Mi hijo no tiene problemas en jugar con todos los niños del pueblo, grandes y pequeños, aunque hay otros niños que veo en el parque que les cuesta jugar si no hay niños de su edad, y esto en estos pueblos es lo que hay. Los fines de semana intentamos hacer cosas, pero en invierno nos quedamos más en casa y entonces somos nosotros, los padres, los que jugamos con él. Supongo que si tuviéramos otro jugarían juntos. Pero bueno, también conozco que son dos y están todo el día peleándose, así que supongo que mejor uno.

La informante empieza explicando que tiene una vida estresada, "entre el trabajo, etc...», tiene horario partido de mañana y tarde en una oficina. Entendemos que tiene dificultades para compaginar su tarea profesional con el hogar y el cuidado de su hijo. Desconocemos la disponibilidad de su marido, pero afirma que «con uno es más que suficiente». Suponemos que tendría dificultades para tener un segundo hijo a nivel económico. Destaca que la vida social en el pueblo es limitada, hay pocos vecinos y niños. Hay pocos menores de su edad y siempre tiene que jugar con los mismos. Cuando se enfadan ya no pueden jugar con ninguno y después deben volver a jugar los mismos. En invierno hacen más vida en casa y el niño debe jugar solo o con sus padres. Con un segundo hijo jugarían más entre ellos, aunque 
también habría peleas y más conflictos. Finaliza su reflexión afirmando que "así supongo que es mejor uno», entendemos que se ha conformado y ha aceptado tener solamente un hijo dadas las circunstancias sociales y económicas de la familia. Seguimos con las aportaciones de Teresa, tiene una hija de 15 años y vive en las afueras de Barcelona, en un entorno urbano:

Tengo una hija de 15 años. Ahora mismo está en la adolescencia, pero siempre ha sido muy exigente con nosotros. Supongo que por ser hija única y la más pequeña de todos los nietos. Mis padres la han criado y nosotros cuando llegábamos a casa no teníamos ganas de enfados y cedíamos rápido a lo que quería. Al no tener más hermanos le hemos dado de todo, con dos o más hijos no hubiera sido lo mismo. Supongo que se crían diferentes si son uno sólo o hay más hijos. Mi marido trabaja y yo a temporadas así que para los tres hemos ido haciendo, y con la ayuda de mis padres, hemos ido bien. A mi hija se lo hemos dado todo y supongo que eso tampoco es bueno, pero eso lo vemos ahora. Ahora estamos pasando una etapa difícil, está muy rebelde y todo el día con las amigas y el móvil. Aquí al estar cerca de Barcelona, coge el metro y se va a comprar con las amigas, de tiendas por Barcelona. Cada día se vuelve más exigente y no valora nada de lo que tiene. Quiero pensar que esto es pasajero y cuando sea adulta será diferente o la vida ya la pondrá en su sitio, ¡nosotros no podemos más!

Teresa describe sus vivencias con su hija. Viven en un entorno urbano, cerca de la ciudad de Barcelona. La menor tiene 15 años y está en plena adolescencia. Está fuertemente influida por su grupo de iguales (amigas). Su hija ha estado cuidada principalmente por sus abuelos y sus padres trabajaban o estaban haciendo otras cosas. La madre se cuestiona la educación dada a su hija, dice «al no tener hermanos le hemos dado de todo, con dos o más hijos no hubiera sido lo mismo». Ser hija única ha influido en la relación con sus padres, con más hermanos debería haber compartido y repartido los recursos. En la actualidad está muy rebelde, siempre con sus amigas y separándose y alejándose de sus padres. La madre está preocupada y parece un poco desbordada por la situación actual. No sabe cómo será el futuro, pero necesariamente debe cambiar su actitud. La madre cuestiona la educación dada a su hija y piensa que de poder volver al pasado realizaría cambios, por ejemplo, enseñar a gestionar mejor el tiempo, el dinero... Olga es madre de una hija de 32 años y reside en Girona, en un entorno urbano:

Mi hija ya tiene 32 años, es maestra. Siempre ha sido una niña muy responsable y educada. Nosotros hemos estado mucho con ella. Vivimos en una ciudad y siempre hemos hecho de todo, hemos salido muchísimo a espectáculos, al camping... pues al no tener a nadie más con quien jugar en casa, siempre hemos pensado que tenía que relacionarse con otros niños y niñas. En la ciudad los familiares los tenemos lejos y había pocas ocasiones en las que quedar con los sobrinos. No hemos tenido problemas importantes con ella, siempre ha sido muy 
fácil. También ha sido una niña que era querida por todos, en el colegio, en las actividades que hacía... siempre ha sido una persona muy entregada a las otras e incluso hacia nosotros, siempre está pendiente de su padre y de mí. El hecho de haber sido hija única supongo que ha tenido siempre un sentido de responsabilidad hacia nosotros y hacia los demás que a lo mejor no se da tanto en familias con más hijos.

La informante explica la relación con su hija, en la actualidad tiene 32 años. La define como una "niña muy responsable y educada». Los padres han sido conscientes de las características de su hija por ser hija única y tener a priori menos posibilidades de socialización. Han tenido una relación muy próxima con ella, siempre han estado y la han llevado a muchos sitios, espectáculos... y han creado situaciones controladas para poder relacionarse con iguales. No ha tenido problemas destacados, al contrario, ha sido una niña muy querida por todos y en diferentes entornos. También, no se ha cerrado en sí misma y tiene una mirada hacia los otros, la familia y la comunidad. Olga valora muy positivamente la educación y la forma de ser de su hija.

Estas han sido las valoraciones y reflexiones presentadas por las madres entrevistadas. Vemos como las experiencias han sido diferentes y variadas. En dos casos la situación es positiva y aceptada, no se cuestionan la decisión de tener solamente un hijo; solamente Teresa manifiesta claramente desaprobación y tener una relación con su hija inadecuada. En todo caso, sus abuelos han sido los responsables de estar más tiempo con la niña. También afirma tener déficit en la gestión de los recursos.

A continuación, siguen las opiniones de los hijos únicos entrevistados, todos ellos tienen más de 18 años. Arnau tiene en la actualidad 25 años y reside en Barcelona:

Para mí ser hijo único no ha sido ningún trauma, además en mi clase tanto en primaria como en secundaria había bastantes compañeros como yo. Así que entre nosotros hacíamos grupo. Quizás los que tenían hermanos eran más movidos y yo y tres o cuatro que íbamos juntos y éramos hijos únicos, éramos más tranquilos. Supongo que al estar en la misma situación nos entendíamos mejor. Eso sí, lo que más me preocupaba de pequeño era quedarme sólo, sin amigos, pero al estar en la misma situación unos cuantos de la clase, pues compartíamos las penas. Además, al vivir en una ciudad grande siempre hay cosas que hacer y al final conocías a gente del barrio que iban a ver los espectáculos, cómo nosotros. Supongo que también depende de los padres, los míos me han acompañado siempre mucho, en todos los momentos. También creo que he tenido más posibilidades de hacer cosas por ser hijo único, como realizar estudios a fuera, que si hubiéramos sido más en casa quizás no se lo podrían haber permitido. Actualmente estoy acabando un Máster en Inglaterra. Me considero una persona 
responsable e independiente y mi vida social la considero satisfactoria, ¡no tengo ninguna queja!

Empieza sus reflexiones diciendo que ser hijo único no ha sido «ningún trauma» como si hubiese un imaginario negativo y traumático hacia el hijo único que no ha sido en su caso. El informante explica que en su clase había varios compañeros también hijos únicos y entre ellos había afinidades. No ha tenido hermanos, pero ha tenido muchos amigos, los cuales eran parecidos, más tranquilos y les gustaba estar juntos. Arnau cree que los hijos únicos son en general más tranquilos. La educación del hijo único depende principalmente de las capacidades y voluntad de los padres y no tanto por ser hijo único. En su caso se ha sentido apoyado y acompañado por sus padres. Además, hay un tema económico importante, los padres pueden gastar más dinero cuando hay un hijo; con dos se deben repartir los recursos. Termina sus reflexiones afirmando que «me considero una persona responsable e independiente y mi vida social la considero muy satisfactoria». En cambio, el siguiente informante ha tenido más dificultades para relacionarse con sus iguales. Gerardo tiene 19 años y vive en un pueblo de la provincia de Lleida:

Siempre me ha costado tener amigos. Me ha costado siempre relacionarme con los demás. Tengo un carácter más bien cerrado. En el colegio no me gustaba jugar con los demás, los veía muy violentos. Además, a mí no me gusta el futbol y no lo entiendo. A mí me gusta estar más en casa o trabajando en el campo, con el tractor. Mis padres tienen terrenos y ayudo a mi padre en la finca. Yo allí soy feliz, cuando salgo de allí no me gusta, no sé qué decir y me quedo callado. Los sábados quedo con los amigos para salir de fiesta, pero me tomo dos cervezas y me voy para casa, la verdad es que no me gusta mucho el ruido. Prefiero quedarme a cenar en casa y luego vamos a hacer unas copas y esto es todo.

El entrevistado vive en un ámbito rural, con poca población y pocos niños y jóvenes de la edad de Gerardo. Afirma haber tenido siempre problemas para relacionarse, dice tener un "carácter más bien cerrado». El informante iba a la escuela del pueblo, pero cuando salía iba a casa a ayudar a sus padres en las labores del campo. Afirma que en el campo es feliz, sabe sus tareas y como realizarlas; en cambio, la vida social con sus iguales le parece más compleja, caótica e imprevisible. Le gusta más quedarse en casa principalmente por ser un entorno más controlado y previsible. La siguiente entrevistada tiene 32 años y reside en la actualidad en Barcelona ciudad, pero nació y vivió sus primeros años en un pueblo de la provincia de Girona. Ana dice:

Actualmente estoy trabajando en Barcelona, en el Clínic (Hospital). Pero soy de un pequeño pueblo. Siempre me ha gustado mucho salir y siempre me ha 
gustado ser la organizadora de todos los eventos. Me gusta llevar las riendas de las situaciones y me cuesta delegar. Cómo soy hija única siempre he decidido por mi sola y supongo que lo continúo haciendo. Para mí ha sido una ventaja, no he tenido ningún problema. Conozco amigas que no tienen apenas relación con sus hermanos. Para mi ser hija única no ha sido ningún problema y creo que por este motivo soy más independiente, ¡me he tenido que buscar más la vida!

La entrevistada es facultativa en un hospital de Barcelona y nació y se crió en un pueblo de la provincia de Girona. Ana ha sido y es una persona activa que se ha relacionado con mucha gente, se siente una líder, «siempre me ha gustado ser la organizadora de todos los eventos». Ser hija única ha conllevado haber de decidir siempre sola, sin poder consultar con una hermana... Por este motivo se siente más fuerte e independiente que otras mujeres con hermanas. Destaca también que en muchos casos los hermanos apenas tienen relación entre ellos, por tener prioridades e intereses diversos.

Se han explicado las aportaciones de los hijos únicos, con entornos y realidades sociales y personales diversas. Las valoraciones son positivas en los tres casos, no consideran ser hijo único una desventaja, en todo caso destacan que les ha ofrecido más posibilidades. Solamente Gerardo describe que es un joven con dificultades de relación con sus iguales. En su caso influye ser hijo único y vivir en un entorno rural con pocas posibilidades de socialización y un negocio familiar muy individual.

Seguidamente nos centramos en las reflexiones de los profesionales de la educación. Laura es profesora de secundaria en un centro público de Girona, afirma:

Creo que cada año hay más hijos únicos, ¿no sé el motivo?, quizás la crisis económica y todo esto, ¿no lo sé? Antes eran pocos o quizás eran un poco diferentes, no sé, se les notaba algo diferente, como que no jugaban tanto y les costaba más relacionarse entre ellos. Ahora como son más, la relación entre ellos ha cambiado, están en una situación de más igualdad. Ahora apenas hay diferencias. Ahora, por ejemplo, en mi clase de ciencias tengo 29 alumnos de los cuales 14 son hijos únicos. También hay el caso de hermanos que tienen casi 15 años de diferencia. En mi familia uno tiene un hijo de 23 años y una niña de 6 años. Todo esto es debido a separaciones y nuevas parejas. Muchos hermanos ahora tienen mucha diferencia de edad y diferentes padres. En estos casos como si fuesen hijos únicos, ¡Imagínate!, cuando la pequeña tenga 20 años y hermano tendrá 37 años.

La entrevistada presenta una mirada general de su grupo clase. Cada año hay más hijos únicos, pero desconoce el motivo, quizás por la crisis económica u otros aspectos sociales y culturales. En su grupo clase en la actualidad casi la mitad son hijos únicos y considera que las dinámicas y relaciones sociales entre los alumnos han cambiado en los últimos años. 
En la actualidad los hijos únicos son un grupo mayoritario y están más integrados. Además, hay familias con hermanos con una diferencia de edad de 15 años, estos no son hijos únicos, pero como si lo fuesen. La profesora reflexiona sobre la situación que antes, sin concretar, había menos hijos únicos y podían sentirse más aislados y menos integrados al grupo clase. En la actualidad son un colectivo mayoritario e imponen sus formas de hacer. Noemí es maestra de primaria en una escuela rural de Lleida:

Yo soy maestra en una escuela rural de un pueblo, a unos 30 quilómetros de Lleida. Tengo 16 niños en clase y 9 son hijos únicos. Como ves más de la mitad. La característica de los niños es variada y no puede trazarse un denominador común ¡hay de todo! niños, niñas, diferentes niveles educativos y económicos de los padres, padres funcionarios, trabajos manuales, padres más jóvenes y con más de 50 años.... No creo que pueda trazarse una tipología clara de los padres con un hijo. Lo que si veo es que muchos padres tienen su primer y muchas veces su único hijo mayores, pasados los 40 y en algunos casos pasados los 50. Supongo que cuesta mucho la estabilidad económica o por ejemplo en el caso de los maestros, cuesta tener una plaza y cuando la tienes estás muchos años fuera de casa. Hasta que no tienes la plaza que quieres pueden pasar 15 años o más. También veo que muchos hijos únicos los fines de semana no tienen muchas relaciones con otros. Yo lo sé porque me lo dicen. El lunes siempre les pregunto qué han hecho el fin de semana y muchos dicen que nada, solamente consola, tele, tableta... Muchos niños en invierno el fin de semana no salen de casa y están siempre solos con sus padres o sus abuelos. [...] Otros niños por el contrario explican actividades muy ricas e interesantes realizadas el fin de semana. Todo esto lo sé yo porque me lo cuentan.

La maestra explica que en su grupo clase más de la mitad de los alumnos son hijos únicos, representan un colectivo mayoritario. No pueden compararse situaciones familiares ya que hay diferencias significativas en las profesiones de los padres, estudios..., dice «no creo que pueda trazarse una tipología clara de los padres con un hijo». Noemí reflexiona sobre un ámbito que conoce de primera mano, aprobar unas oposiciones de maestra y tener la plaza deseada puede durar hasta «15 años o más». Muchos padres llegan a la paternidad a los 40 o 50 años con dificultades para buscar el segundo. Resulta interesante la observación de la maestra sobre la tarea de los lunes sobre las actividades realizadas el fin de semana por los niños. Muchos afirman no realizar nada, solamente estar en casa, jugar en la consola, ver la televisión... En el caso de los hijos únicos resulta más preocupante ya que se socializan e interaccionan reiteradamente solos con los aparatos tecnológicos. Otros realizan actividades interesantes y variadas. Santiago, profesor de secundaria en un centro de secundaria de Girona: 
El tema de la familia es preocupante, también de los hijos únicos. Muchos padres no están o no están el tiempo que deberían estar. En muchos casos principalmente están los abuelos y ellos no quieren lidiar y luchar con sus nietos. La relación que tienen los abuelos con los nietos es muy diferente que la relación que tienen los padres. Hablando de los hijos únicos, en muchos casos, quienes están más tiempo con ellos son los abuelos y hacen lo que quieren. Los padres siempre están trabajando, los padres y las madres. [...] En mi centro tenemos bastantes hijos únicos y vemos también que como más hermanos hay, la familia más dificultades económicas tiene. En nuestro barrio hay familias con problemas económicos y lo sabemos; también, las familias llegadas de otros lugares, de África, de Suramérica... tienen más hijos que las familias de aquí. Muchas veces vemos y pensamos los profesores, la familia de tal ya tiene dos hermanos y lo pasan mal, tienen dificultades económicas y va la madre y me dice contenta, «estoy otra vez embarazada», me dicen que todos son niños y quieren la niña. Son gente que tienen muchas dificultades y ahora serán uno más.

El profesor destaca un aspecto de las familias actuales, la entrada de las mujeres masivamente al mercado laboral. La salida de la madre del hogar en muchos casos no se ha compensado por la entrada del padre. Muchos padres han actuado igual, sin cambiar dinámicas y responsabilidades laborales. Los abuelos han ocupado el lugar dejado por las madres y son ellos los que están y educan a sus nietos. En muchos casos la relación de los padres con sus hijos es lejana y fría, teniendo consecuencias a medio y largo plazo. Muchos hijos únicos pasan demasiadas horas con sus abuelos, jugando solos (tal como explicaba Noemí con los aparatos tecnológicos). Santiago relaciona posibilidades económicas de las familias con el número de hijos. Los hogares con un hijo tienen menos dificultades monetarias que aquellas con más. También establece la relación entre migración, familias llegadas de otras culturas (tienen la tendencia de querer más hijos) pero en las sociedades occidentales muchos niños implican para las familias, menos recursos y menores posibilidades sociales y educativas para sus hijos.

Se ha presentado información cuantitativa de los países de la Unión Europea y España sobre porcentajes de hogares con el número de hijos. Los datos muestran cómo la tipología mayoritaria de los hogares en Europa y España es una familia sin hijos, pero dentro de las diversas posibilidades de hogares con niños, la mayoritaria es tener solamente uno. También se asocia el número de hijos con el riesgo de pobreza relativa y los datos dicen que con más hijos más riesgo. También se han realizado 15 entrevistas ( 5 madres, 5 hijos únicos y 5 profesores), aunque solamente se han mostrado en la investigación las aportaciones de 9 (3 madres, 3 hijos y 3 docentes) describiendo situaciones vividas. 


\section{CONCLUSIONES}

El artículo ha pretendido mostrar una realidad social y cultural conocida por los ciudadanos, pero curiosamente poco abordada por los investigadores sociales. Se han presentado datos cuantitativos sobre la evolución de las familias europeas y españolas y comprobamos que los hogares europeos en 2016 según el número de hijos, el 47\% tenían un hijo, el 40\% tenían dos y el $13 \%$ tenían tres. En Europa casi la mitad de los hogares con hijos solamente tienen uno, ésta es una opción mayoritaria. Lo Castro (2017) reitera que en la actualidad las familias tienen menos hijos por diferentes motivaciones; principalmente por la incorporación de la mujer al mercado laboral y la escasa atención de los hombres a estas tareas; también en algunos casos por priorizar los adultos su propio bienestar. Teniendo la consecuencia la reducción de los miembros de las familias.

En España se sigue la misma tendencia, a partir del 2011, las parejas con un solo hijo superan en número a las parejas con dos y en el último año que tenemos datos, el 2016 continúa igual. En relación con el riesgo de pobreza relativa según el tipo de hogar en España, en diferentes años, vemos como hay diferencias significativas. Aquellos hogares sin hijos dependientes a cargo en 2015 tienen el riesgo de pobreza en el 16,8\%, aquellos hogares con hijos dependientes a cargo suben hasta el $27,4 \%$, un adulto con uno o más niños dependientes el 37,5\%. Se establece una relación entre el número de hijos en el hogar y el riesgo de pobreza; tal como escriben Allepuz y Rosell (2014), en los últimos años en España ha disminuido el riesgo de pobreza de las personas mayores y ha aumentado significativamente para los niños. En la misma línea, Bayrakal y Kope (1990) hacen referencia a más disfunciones familiares en determinadas tipologías familiares con un hijo único, por ejemplo, destaca la modalidad de padre soltero con su hijo.

Las aportaciones de los entrevistados también resultan iluminadoras para comprender la irrupción de los hijos únicos. Arnau tiene 25 años y afirma claramente que ser hijo único no es una desventaja, al contrario, a él le ha favorecido. Sus padres le han acompañado en todo momento y una parte importante de los recursos monetarios de la familia han ido prioritariamente para él; en la actualidad está cursando un Máster en Inglaterra, seguramente con más hermanos no sería posible. En la misma línea, Teresa, madre de una niña de 15 años, explica que su hija lo ha tenido todo, pero no lo ha aprovechado. Los padres no han podido estar el tiempo suficiente con la niña y principalmente han estado los abuelos. La hija ha tenido recursos, pero no el apoyo y cercanía de sus padres. Su madre dice que ahora está muy rebelde. Olga, madre de una hija de 32 años, afirma que siempre 
han hecho un esfuerzo para socializarla con otros niños. Afirma, «nosotros hemos estado mucho con ella» y la define como una persona querida por todos. La realidad de ser hijo único es vivida de forma desigual en función del entorno y de las capacidades sociales, culturales, educativas y económicas de los padres. En todas las aportaciones presentadas se destaca la importancia del apoyo y cercanía de los padres hacia sus hijos. Tal como explican Rosenberg y Hyde (1992) hay diferentes modalidades y diferencias relevantes entre las familias y los hijos únicos. No constituyen un bloque estable y homogéneo.

En todo caso, las familias con un solo hijo tienen algunas características concretas. Pitkeatheley y Emerson (1998) alertan sobre la reducción de relaciones sociales dentro de la familia con un solo hijo, en las cuales siempre involucra a un adulto (padre o madre). Esta situación puede incrementar la tensión y la confrontación entre el hijo único y sus padres, tal como explica alguna entrevistada. Por el contrario, también los padres focalizan sus energías y esfuerzos hacia un único objetivo. Lien-Tan (2014) explica que en China los hijos únicos se han convertido en el centro de atención de sus familias. Los adultos (padres y abuelos) concentran todas sus expectativas hacia su hijo.

Seguidamente se presentan algunas posibles futuras líneas de investigación y limitaciones de la investigación. Se podrían realizar análisis más pormenorizados, entrar en detalle de diferentes características de familias y cada una de ellas como socializan y educan a su hijo único. También se podría abordar la relación entre familia e hijo único desde una perspectiva comparativa entre diferentes países, posibles diferencias entre comunidades autónomas, entre ámbito rural y urbano. Sería interesante profundizar en historias de vida de padres (de hijos únicos) y/o hijos únicos para comprender sus itinerarios vitales. Analizar posibles diferencias entre hijos e hijas únicas. En todo caso, consideramos que estudiar la irrupción del hijo único en las sociedades avanzadas requiere un abordaje amplio desde diversas disciplinas.

Para ir finalizando, en los últimos años las sociedades occidentales se han transformado radicalmente siguiendo un proceso de individualización en todos los ámbitos sociales y culturales. Cambiando inercias en las familias e individuos. Daros (2018) afirma que las personas están ávidas de individualidad y la irrupción del hijo único sigue la misma tendencia social y cultural. Laura dice que cada año hay más hijos únicos en clase, antes eran una minoría y en la actualidad son mayoría y construyen y definen estructuras y relaciones. Santiago señala que algunas familias con más hijos tienen más dificultades monetarias y más riesgo de pobreza. Todas estas 
aportaciones van más allá de sus propias vivencias particulares y se pueden extrapolar a una dimensión más general. Permiten comprender un cambio de paradigma y el afianzamiento de nuevas organizaciones familiares, más ajustadas a las necesidades del individualismo posmoderno. La opción familiar de tener solamente un hijo ofrece más posibilidades de integración y éxito a estos niños. Tal como explica Lien-Tan (2014) en referencia a China en la actualidad, quizás en un futuro próximo la élite económica, política e intelectual de los países occidentales, también en España, esté integrada principalmente por hijos únicos.

\section{REFERENCIAS}

Ander-Egg. E. (2000). Métodos y técnicas de investigación social. Buenos Aires: Lumen-Humanitas.

Allepuz, R., y Rosell, M. J. (2014). Anatomía de la pobreza a Catalunya. Lleida: Pagés.

Aranda, C., y Chávez, L. (2017). Autoconcepto y habilidades sociales en niños como hijos únicos y niños con hermanos. PsicoEducativa: reflexiones y propuestas, 3(5), 38-44. Recuperado de: https://psicoeducativa.iztacala.unam.mx/revista/index. php/rpsicoedu/issue/view/7.

Bauman, Z. (2003). Modernidad líquida. México, DF: Fondo de Cultura Económica.

Bayrakal, S., y Kope (1990). Dysfunction in the single-parent and only-child family. Adolescence. 25(97), pp. 1-7. Recuperado de: https://www.ncbi.nlm.nih.gov/ pubmed/2333790.

Beck, U. (1998). La sociedad del riesgo: hacia una nueva modernidad. Barcelona: Paidós.

Daros, W. (2018). La educación entre la posmodernidad globalizada y la sociedad seductora según G. Lipovetsky. Revista Cultura Económica. Año XXXVI (95), 59-74. Recuperado de: http://erevistas.uca.edu.ar/index.php/CECON/article/view/1519

Elzo, J. (2000). El silencio de los adolescentes: lo que no cuentan a sus padres. Madrid: Temas de hoy.

Falbo, T., y Poston, D. L. (1993). The Academic, Personality and Physical outcomes of only children in China. Child development, 64(1), 18-35. Recuperado de: https:// www.jstor.org/stable/1131435?seq=1\#page_scan_tab_contents.

Giddens, A. (2000). Un mundo desbocado: los efectos de la globalización en nuestras vidas. Madrid: Taurus.

Lien-Tan, P. (2014). La planificación familiar en China: la política de un solo hijo por familia. Estudios de Asia y África, vol. XLIX (1), 173-192. Recuperado de: https:// estudiosdeasiayafrica.colmex.mx/index.php/eaa/article/view/2058/2058

Lipovetsky, G., y Charles, S. (2006). Los tiempos hipermodernos. Barcelona: Anagrama. 
Liu, C., Munakata, T., y Onuoha, F. N. (2005). Mental heatlh condition of the only-child: a study of urban and rural high school students in China. Adolescence. 40(160), 831-845. Recuperado de: https://www.ncbi.nlm.nih.gov/pubmed/16468675.

Lo Castro, D. (2017). Hijos y composición familiar. Tesis doctoral presentada en la Universidad de Extremadura. Recuperado de: http://dehesa.unex.es/handle/10662/6188.

Pitkeathley, J., y Emerson, D. (1998). Ser hijo único. Manual de supervivencia. Barcelona: Paidós.

Rosenberg, B., y Hyde, J. (1992). The only child: is there only one kind of only? The Journal of Genetic Psychology, 154(2), 269-282. Recuperado de: https://www.tandfonline.com/doi/abs/10.1080/00221325.1993.9914740.

Tahull, J., y Montero, I. (2015). Malestar en la escuela. Conflicto entre profesores. Revista Educar, 51(1), 169-188. Recuperado de: https:/educar.uab.cat/ojs-educar/ educar/article/view/v51-n1-tahull-montero.

Tahull, J. (2016). La compleja transición de los adolescentes hacia la vida adulta. Revista de Antropología experimental, 16(1), 27-44. Recuperado de: https://dx.doi. org/10.17561/rae.v0i16.2853.

Tahull, J., Molina, F., y Montero, I. (2017). Malestar familiar. ¿Tiene incidencia la pobreza infantil y juvenil en los resultados académicos? Revista Análisis. 49(90), 39-62. Recuperado de: https://doi.org/10.15332/s0120-8454.2017.0090.02.

Wang, H., y Zhu, R. (2019). China's only Children and their spillover effects on academic performance in the classroom. The B.E. Journal of Economic Analysis and Policy. doi: 10.1515/bejeap-2019-0058

Wang, Q., Leichtman, M., y White, S. (1998). Childhood memory and self-description in young chinese adults: the impact of growing up an only child. Cognition, 69(1), 73-103. Recuperado de: https://www.sciencedirect.com/science/article/pii/ S0010027798000614.

Winnicot, D. W. (1973). Il bambino e la famiglia. Firenze: Giunti-Barbera.

Yang, J., Hou, X., Wei, D. et al. (2017). Only-child and non-only-child exhibit differences in creativity and agreeableness: evidence from behavioral and anatomical structural studies. Brain Imaging and Behavior. 11(2), 493-502. Recuperado de: https://doi.org/10.1007/s11682-016-9530-9. 


\section{Anexo 1 ENTREVISTA A MADRES Y PADRES}

1. ¿Cómo te llamas?, ¿Dónde vives? ¿Con quién?, ¿Cuántos años tienes?

2. ¿A qué te dedicas?

3. ¿Te has planteado tener más hijos? ¿Por qué?

4. ¿Qué opinión tiene tu marido/esposa sobre tener solamente un hijo?

5. ¿Cómo ve la sociedad a los hijos únicos? ¿ ¿ $u$ vida es más fácil o más difícil?

6. ¿Piensas que las relaciones que ha establecido o establece tu hijo/a con otros niños/as, adolescentes, adultos, maestros... son diferentes a las que tendría si tuviera hermanos? ¿Por qué?

7. ¿Qué tipo de relaciones sociales se establecen entre padres e hijo/a dentro de la familia?

8. ¿Consideras que ser hijo único puede influir de alguna manera en su futuro?, ¿Por qué?

9. ¿Cuáles son las ventajas e inconvenientes de ser hijo único?, también de sus padres. 


\section{ANEXo 2 \\ ENTREVISTA A HIJOS/AS ÚNICOS/AS}

1. ¿Cómo te llamas?, ¿Dónde vives?, ¿Cuántos años tienes?

2. ¿A qué te dedicas?

3. ¿Qué significa para ti ser hijo/a único/a?

4. ¿Consideras que existen diferencias (de cualquier tipo, personales, emocionales, económicas, educativas) entre las personas que son hijos/as únicos/as y las que no lo son? ¿Por qué?

5. ¿Cómo ve la sociedad a los hijos únicos?, ¿Su vida es más fácil o más difícil?

6.. ¿Ser hijo único ha tenido alguna relación con la escuela: relaciones profesores, resultados académicos?

7. ¿Piensas que las relaciones que tienes con la gente: amigos, compañeros, adultos, profesores... son diferentes que si tuvieras hermanos? ¿Por qué?

8. ¿Qué opinas sobre las relaciones sociales dentro de la familia?, ¿Cómo son?

9. ¿Cuáles son las ventajas e inconvenientes de ser hijo único?, también de los padres. 


\section{Anexo 3}

\section{ENTREVISTA A PROFESIONALES DE LA ENSEÑANZA}

1. ¿Cómo te llamas?, ¿Cuántos años tienes?, ¿Dónde vives?

2. ¿Desde cuándo te dedicas a la enseñanza?

3. ¿Cómo profesional de la educación consideras que existe o podría existir alguna diferencia (personal, emocional, social...) entre el alumnado que es hijo/a único/a y el que no lo es?, ¿Tener más alumnos hijos únicos en clase tiene alguna relación con las dinámicas internas en el aula?, ¿Cómo son estos alumnos?, ¿Cómo son las familias?

4. ¿Tendrías alguna opinión sobre el incremento de esta tipología familiar?

5. ¿Cómo ve la sociedad a los hijos únicos? ¿Su vida es más fácil o más difícil?

6. ¿Piensas que las relaciones que tienen con la gente: amigos, compañeros, adultos, profesores... son diferentes que si tuvieran hermanos? ¿Por qué?

7. ¿Cuáles son las ventajas e inconvenientes de ser hijo único?, también de sus padres. 